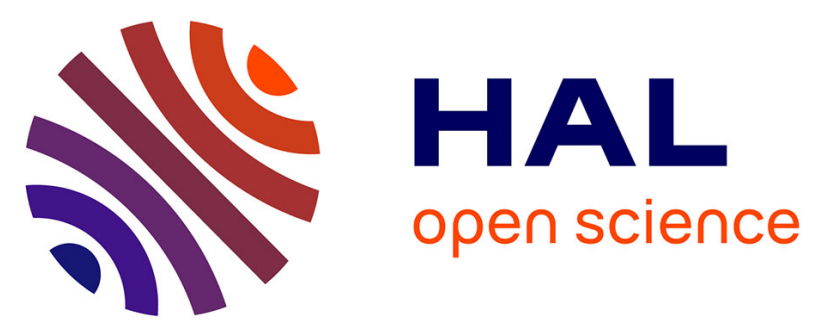

\title{
High strain rate visco-damageable behavior of Advanced Sheet Molding Compound (A-SMC) under tension
}

\author{
Mohammadali Shirinbayan, Joseph Fitoussi, Fodil Meraghni, Benjamin \\ Surowiec, Michel Bocquet, Abbas Tcharkhtchi
}

\section{- To cite this version:}

Mohammadali Shirinbayan, Joseph Fitoussi, Fodil Meraghni, Benjamin Surowiec, Michel Bocquet, et al. High strain rate visco-damageable behavior of Advanced Sheet Molding Compound (A-SMC) under tension. Composites Part B: Engineering, 2015, 82, pp.30-41. 10.1016/j.compositesb.2015.07.010 . hal-01196382

\section{HAL Id: hal-01196382 \\ https://hal.science/hal-01196382}

Submitted on 9 Sep 2015

HAL is a multi-disciplinary open access archive for the deposit and dissemination of scientific research documents, whether they are published or not. The documents may come from teaching and research institutions in France or abroad, or from public or private research centers.
L'archive ouverte pluridisciplinaire HAL, est destinée au dépôt et à la diffusion de documents scientifiques de niveau recherche, publiés ou non, émanant des établissements d'enseignement et de recherche français ou étrangers, des laboratoires publics ou privés. 


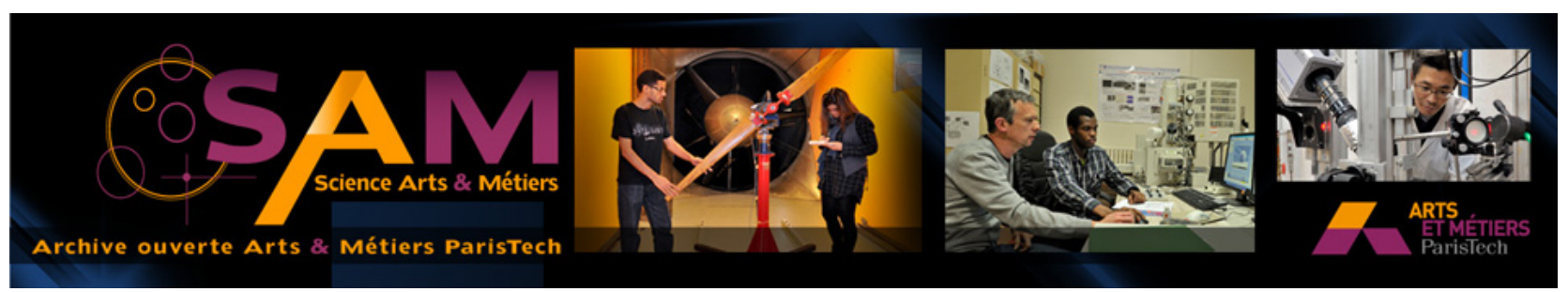

\section{Science Arts \& Métiers (SAM)}

is an open access repository that collects the work of Arts et Métiers ParisTech researchers and makes it freely available over the web where possible.

This is an author-deposited version published in: http://sam.ensam.eu

Handle ID: .http://hdl.handle.net/10985/9971

\section{To cite this version :}

Mohammadali SHIRINBAYAN, Joseph FITOUSSI, Fodil MERAGHNI, Benjamin SUROWIEC, Michel BOCQUET, Abbas TCHARKHTCHI - High strain rate visco-damageable behavior of Advanced Sheet Molding Compound (A-SMC) under tension - Composites Part B: Engineering Vol. 82, p.30-41 - 2015 


\title{
High strain rate visco-damageable behavior of Advanced Sheet Molding Compound (A-SMC) under tension
}

\author{
M. Shirinbayan ${ }^{\text {a, }}{ }^{\text {, }}$ J. Fitoussi ${ }^{\text {a }}$, F. Meraghni ${ }^{\text {b }}$, B. Surowiec ${ }^{\text {c }}$, M. Bocquet ${ }^{\text {a }}$, A. Tcharkhtchi ${ }^{\text {a }}$ \\ a Arts et Métiers ParisTech, PIMM, UMR CNRS 8006, 151 Boulevard de l'Hôpital, 75013 Paris, France \\ ${ }^{\mathrm{b}}$ Arts et Métiers ParisTech, LEM3, UMR CNRS 7239, 4 Rue Augustin Fresnel, 57078 Metz, France \\ ${ }^{\mathrm{c}}$ PLASTIC OMNIUM AUTO EXTERIOR SERVICES, Sigmatech, Sainte Julie, France
}

\begin{abstract}
A B S T R A C T
Advanced Sheet Molding Compound (A-SMC) is a serious composite material candidate for structural automotive parts. It has a thermoset matrix and consists of high weight content of glass fibers (50\% in mass) compared to standard SMC with less than $30 \%$ weight fiber content. During crash events, structural parts are heavily exposed to high rates of loading and straining. This work is concerned with the development of an advanced experimental approach devoted to the micro and macroscopic characterization of A-SMC mechanical behavior under high-speed tension. High speed tensile tests are achieved using servo-hydraulic test equipment in order to get required high strain rates up to $100 \mathrm{~s}^{-1}$. Local deformation is measured through a contactless technique using a high speed camera. Numerical computations have led to an optimal design of the specimen geometry and the experimental damping systems have been optimized in terms of thickness and material properties. These simulations were achieved using ABAQUS explicit finite element code. The developed experimental methodology is applied for two types of A-SMC: Randomly Oriented (RO) and Highly Oriented (HO) plates. In the case of HO samples, two tensile directions were chosen: HO- $0^{\circ}$ (parallel to the Mold Flow Direction (MFD)) and HO- $90^{\circ}$ (perpendicular to the MFD). High speed tensile tests results show that A-SMC behavior is strongly strain-rate dependent although the Young's modulus remains constant with increasing strain rate. In the case of $\mathrm{HO}^{\circ} 0^{\circ}$, the stress damage threshold is shown an increase of $63 \%$, when the strain rate varies from quasi-static $\left(0.001 \mathrm{~s}^{-1}\right)$ to $100 \mathrm{~s}^{-1}$. The experimental methodology was coupled to microscopic observations using SEM. Damage mechanisms investigation of $\mathrm{HO}$ and RO specimens showed a competition between two mechanisms: fiber-matrix interface debonding and pseudo-delamination between neighboring bundles of fibers. It is shown that pseudo-delamination cannot be neglected. In fact, this mechanism can greatly participate to energy absorption during crash. Moreover, the influence of fiber orientation and imposed velocity is studied. It is shown that high strain rate and oriented fiber in the tensile direction favor the pseudo-delamination.
\end{abstract}

\section{Introduction}

Sheet Molding Compounds (SMCs) are high strength glass reinforced thermoset moulding materials processed by thermocompression [1,2]. SMC composites combine glass fiber and unsaturated polyester/phenolic/Vinyl and Acrylic modified resins to produce a high strength molding compound [3-5]. These materials are usually formulated to meet performance requirements of the part to be molded. Moreover, Vinyl-esters resins used for new Advanced SMCs (A-SMC) exhibit many desirable features, including mechanical properties comparable to those of epoxy, excellent chemical resistance and tensile strength, and cost competitiveness. Moreover, its low viscosity enables room-temperature infusion. SMC and A-SMC are ideal for large structural automotive components because of their high strength-to-weight ratio [6,7]. Due to significant tooling investment, overall component cost savings resulting from part consolidation, with the same coefficient of thermal expansion as steel and excellent corrosion resistance; A- 
SMC is an ideal alternative to metals and can be used in the same fluctuating temperature environments $[8,9]$.

Mechanical response of SMC composites is sensitive to the rate at which they are loaded [10-13]. Hence, for the effective use of these composites, their response under different strain rates should be clearly understood. During experimental high speed tests, the composite is generally subjected to rapid accelerations. So, at the beginning of the loading many complex processes occur due to rapid straining coupled to inertial disturbances and test system ringing [12]. Spatio-temporal variations of the strain and stress fields during a high speed test make the analysis more difficult $[12,14]$. Due to these complicated experimental conditions, not enough reliable material data has been determined at typical crash speeds. In order to increase safety, reliable material properties at typical crash speeds are essential for precise simulations of crash processes involving composite parts [15-17]. A first study on a standard SMC composite reinforced with $30 \%$ glass fiber [12] showed that the elastic modulus remains insensitive to the load rate for the explored velocity range; from quasi-static to up to $200 \mathrm{~s}^{-1}$, a rough average value of $13 \mathrm{GPa}$ is found. However, the microstructure variability of this class of materials can bring about a slight discrepancy [10-12] notably for dynamic loadings. Several studies [8-12] showed that the predominant damage mechanism for standard SMC composites is the debonding at the fiber-matrix interface. An experimental methodology [12] based on dynamic tensile tests has contributed to emphasize the strain rate effects on the overall behavior of SMCR2 6 composites. It has been demonstrated that as the strain rate increased, a delayed damage onset is followed by a slightly reduced damage accumulation kinetic. The notion of visco-damaged behavior due to the time-dependent fibermatrix interface strength has been emphasized for this SMC composite. The results of this study have provided the experimental framework to identify and validate a multi-scale model integrating the material microstructure effects [8]. This model is currently implemented into a FE code [18].

In the present paper, an experimental study is carried-out to investigate the strain rate influence on the overall mechanical behavior of a new Advanced SMC. The organization of this work is as follow: after a presentation of the main physical characteristics and microstructure of A-SMC composite, an optimization of high speed tensile test until failure is proposed through finite element analysis using a commercial explicit code (ABAQUS explicit) in order to take into account the perturbations mentioned above. Two kinds of A-SMC microstructures are investigated: Randomly Oriented fibers (RO) and Highly Oriented fibers (HO). In the case of $\mathrm{HO}$ samples, two tensile directions were chosen in order to evaluate the anisotropic effect due to microstructure: $\mathrm{HO}-0^{\circ}$ (parallel to the Mold Flow Direction (MFD)) and HO-90 ${ }^{\circ}$ (perpendicular to the MFD). Moreover, SEM fractography analysis emphasizes the effect of microstructure and strain rate on the main damage and failure micro-mechanisms. At the end of the paper, a special attention is given to the analysis of the pseudo-delamination occurring just before failure. The effect of microstructure and strain rate on the pseudo-delamination is studied.

\section{Material description and methods}

\subsection{Advanced Sheet Molding Compound composite (A-SMC)}

Advanced Sheet Molding Compound composite (A-SMC) consists of high content of glass fibers (50\% in mass corresponding to $38.5 \%$ in volume) in contrast to standard SMC containing a maximum of only $30 \%$ in mass of glass fiber. Standard SMC is classically used in automotive industry for semi-structural part like rear floor or inner panel of a tailgate for instance. A-SMC as a thermoset material is a serious candidate for structural parts (security parts). Raw material (not consolidated) is flexible and stored on rolls. The sheets should be cut from these rolls with adapted size depending on the mold. Then it should be stacked several layers into the mold and close it [1]. The material consolidation is performed by thermo-compression process $\left(\sim 150{ }^{\circ} \mathrm{C}\right.$ and $60-120 \mathrm{~kg} /$ $\mathrm{cm}^{2}$ ). Under these conditions the viscosity of the materials decreases and allows it to fulfill the whole cavity of the mold; this is the first step of the process. Then the materials stay in position with no reticulation for a short duration; this is the second step of the process. The third step of the process consists of a reticulation time of the thermoset material that is the consolidation phase. The duration of whole process for one part is less than $2 \mathrm{~min}$. This low process time is mandatory in automotive industry due to the high production rhythm.

A-SMC is a high mechanical performance SMC based on vinylester resin and reinforced with high ratio of chopped bundles of glass fibers (25 mm length). The composition of A-SMC is shown in Table 1. For the need of this study, two types of A-SMC plates have been provided by PLASTIC OMNIUM AUTO EXTERIOR SERVICES: Randomly Oriented (RO) and Highly Oriented (HO) plates. HO plates have been obtained by an initial charge put only in the left part of a rectangular mold $(30 \times 40 \mathrm{~cm})$ before compression leading to material flow. RO plates were obtained without material flow by completely filling the mold.

However, it would be interesting to have more comprehensive data for the other specimen orientations in order to get a more comprehensive analysis of the damage and induced behavior anisotropy of SMC behavior. However, only two directions have been tested and deeply analyzed for two reasons:

1) The present work aims at comparing the strain rate effect for two typical microstructures (randomly and oriented fibers) in order to define the sensitivity range as upper and lower bounds. In fact, damage behavior is mostly due to fiber matrix interface debonding. The three kinds of performed tests lead to three kinds of predominant local damage mechanisms. These degradation modes occurred for each kind of test are as follow:

- FF- $0^{\circ}$ tests provide fiber breakage and pseudo-delamination,

- FF-90 $90^{\circ}$ tests promote mainly fiber-matrix interface debonding at the $90^{\circ}$ oriented fibers because of the high normal stress for this orientation,

- RO damage initiate at the interface of the $90^{\circ}$ oriented fibers and progressively propagates in the more oriented fiber interfaces.

Furthermore, the rate sensitivity demonstrated in the paper is representative of the strain rate effect on the most commonly observed local damage mechanisms.

2) For this kind of oriented microstructure, performing off-axis tensile tests leads to an induced shear, non-homogeneous stress and strain fields and non-negligible edge effect. Therefore, it will be difficult to get optimized geometry for dynamic tests providing homogeneous fields and constant strain rate.

Table 1

A-SMC composition.

\begin{tabular}{ll}
\hline Product nature & Composition (content in mass percent) \\
\hline Glass fibers & $50 \%$ \\
Vinyl-ester resin & $24 \%$ \\
Filler & $24 \%$ \\
Other products & $2 \%$ \\
\hline
\end{tabular}




\subsection{Methods}

\subsubsection{Characterization methods}

Microscopic observations and image analysis, using Scanning Electronic Microscope (HITACHI 4800 SEM), have been performed in the aim to investigate qualitatively the material microstructure and especially fibers orientation. In order to measure the main transitions temperatures, thermo-mechanical (DMTA) tests have been performed on RO samples using DMA Q800 instrument, from TA Company. The tests have been realized at following condition: alternating bending configuration; temperature range $-100{ }^{\circ} \mathrm{C}$ to $250{ }^{\circ} \mathrm{C}$; frequency $1 \mathrm{~Hz}$; temperature rate $2^{\circ} \mathrm{C} / \mathrm{min}$.

\subsubsection{High-speed tensile tests}

2.2.2.1. Testing devices. High-speed tensile tests have been performed upon a servo-hydraulic test machine. As specified by the manufacturer (Schenk Hydropuls VHS 5020), the test machine can reach a crosshead speed range from $10^{-4} \mathrm{~m} / \mathrm{s}$ (quasi-static) to $20 \mathrm{~m} /$ s. Moreover, the load level is measured by a piezoelectric crystal load cell having a capacity of a $50 \mathrm{kN}$. High-strain rate tensile tests were conducted at different strain-rates until the composite specimen total failure. The test machine is equipped with a launching system. The A-SMC specimen is positioned between the load cell (upper extremity) and the moving device (lower extremity) as sketched in Fig. 1.

2.2.2.2. Optimization. Prior to the contact between the sliding bar and the hydraulic jack (see Fig. 1), the latter one is accelerated over a straight displacement of $135 \mathrm{~mm}$ (for maximum strain rate) in order to reach the nominal crosshead velocity before the load begins. Once the contact occurs, the specimen is then subjected to tension. The damping joint placed between the slide and the hydraulic jack has been experimentally optimized (material choice and geometry) in order to attenuate partially the perturbation due to mechanical waves caused by the dynamic shock and also to limit the system ringing [12] related to the hanging mass of the upper fixing system.

As pointed out above, the damping joint inserted between the sliding bar and the tube of the hydraulic jack enables a partial absorption of the generated stress wave. Nevertheless, the damping

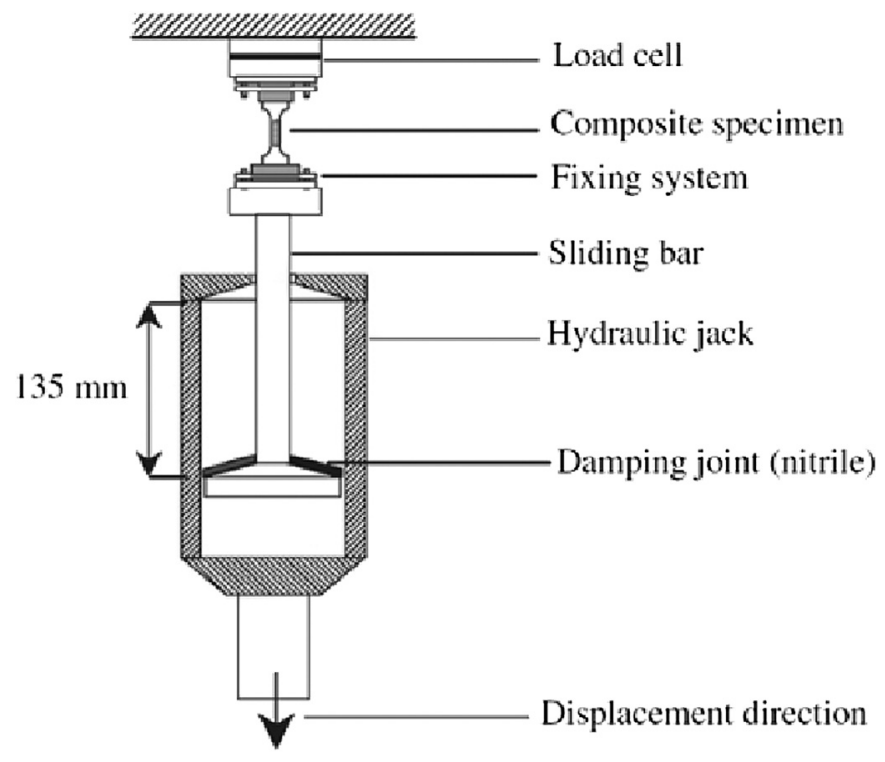

Fig. 1. Experimental device used for high-speed tensile tests. joint must be able to attenuate the shock wave during its compression. Moreover, in order to ensure the derivation of the Young's modulus, the joint compression must be completely finished before the end of the complete elastic deformation of the specimen. It is obvious that it affects the loading rate. An optimal design of the damping joint, in terms of constitutive material and geometry, may result in a constant strain-rate and in homogeneous strain and stress fields in the central zone of the composite specimen. We have chosen a damping joint consisting of a low impedance material: rubber nitrile ( $1.5 \mathrm{~mm}$ thickness).

2.2.2.3. Specimen geometry. Furthermore, specimen geometry has to be optimized in order to reduce the perturbation wave's effect. The idea is to produce a reduction of the stress wave propagation occurring for a high-speed tensile test by mean of brutal variation of the specimen mechanical impedance. This variation of mechanical impedance leads to the trapping of the mechanical waves in the lower part of the testing device far from the specimen.

Therefore, the composite specimen geometry has been optimized as a result of numerical computations using ABAQUS finite element (FE) code. The criterion used for the optimization consists in reaching a stabilized strain distribution and strain rate within the specimen gauge section at the beginning of the loading stage. The optimization procedure relies upon coupling FE numerical results and experimental data. It falls into four stages (Fig. 2):

i A tensile test is conducted at a fixed displacement rate. The displacement induced at specimen extremities is measured. The damping joint, positioned between the sliding and the hydraulic jack, may limit the shock effect until its maximal compression. Thus, at the beginning of the loading, a part of the total imposed displacement is consumed by the compression of the damping joint. It should be pointed out that the damping joint would be completely compressed before the end of the total elastic deformation of the specimen. Consequently, the specimen (which is placed in series with the damping joint) is submitted to a progressive acceleration until the total compression of the damping joint. Then, at the so called rise time $\left(t_{r}\right)$, the displacement rate induced at specimen extremities becomes constant. Beyond this time, the composite specimen is therefore subjected to a dynamic tensile loading at constant strain rate. The first stage aims then at estimating experimentally the rise time $\left(t_{r}\right)$ (see Fig. 2(a)). Its value lies in the range $\left[10^{-4}\right.$ to $\left.10^{-5} \mathrm{~s}\right]$ and depends on the adopted joint thickness and the nominal test velocity.

ii Once the rise time is evaluated, boundary conditions are numerically applied on the specimen extremities in terms of imposed velocity, in order to compute the dynamic response of the specimen, according to Fig. 2(b): a linear increase of the velocity until the imposed value which is reached at the rise time.

iii On the basis of the FE simulations and assuming that the specimen behaves like an elastic anisotropic solid, a recursive optimization procedure results in the determination of optimal geometrical parameters: $\mathrm{L}_{1}, \mathrm{~L}_{2}, \mathrm{~L}_{3}$ and $\mathrm{R}$ (Fig. 3 ). These parameters are those of a dumbbell-shaped specimen as sketched in Fig. 2(c) and are optimized in such a way of reducing the stress wave effects in the overall response through a rapid loss of mechanical impedance. Finally, the optimization aims at generating homogeneous stress/strain field and constant strain rate at the effective zone of the specimen. In order to keep a minimum volume of the sample (Representative Volume Element), width and length of the specimen have been fixed to $10 \times 20 \mathrm{~mm}$. Fig. 4(a) shows, for different values of radius and applied displacement velocity, the minimum stress at which the 


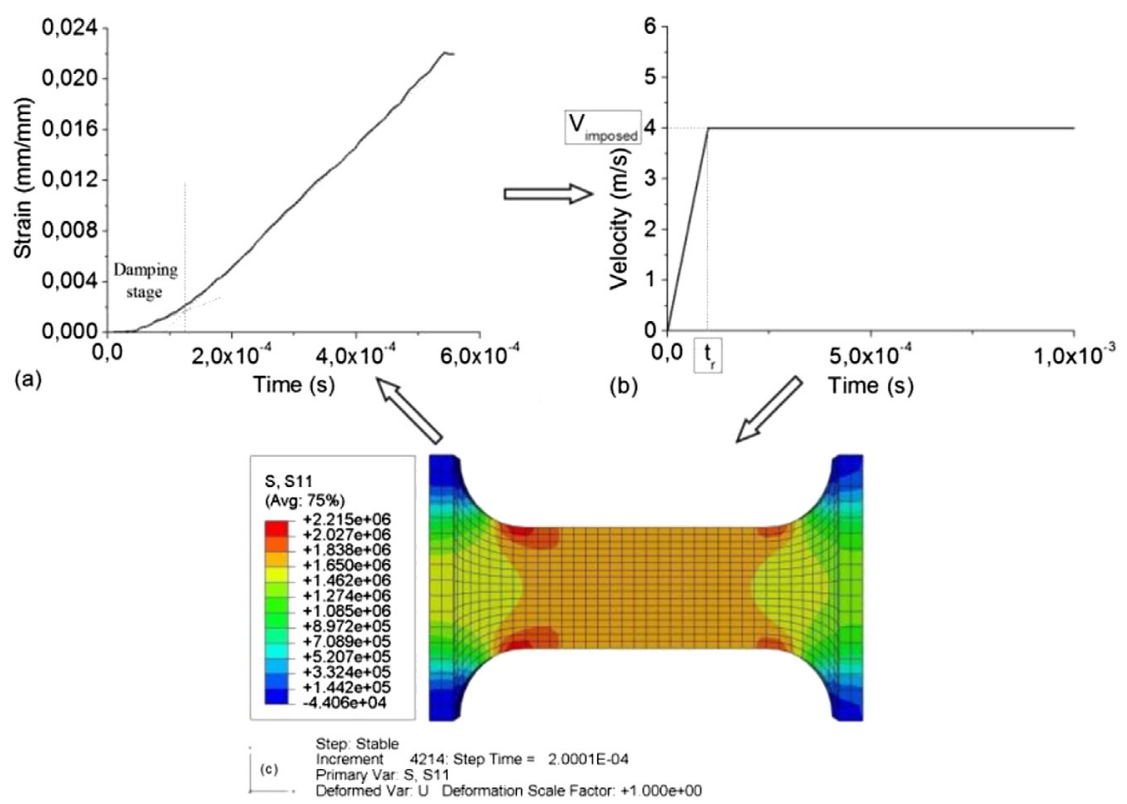

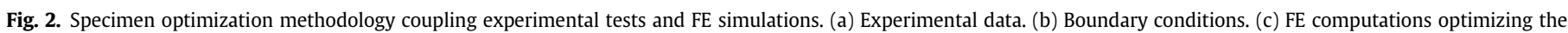
dumbbell-shaped specimen geometry parameters.

\begin{tabular}{c|c|ccccc}
\hline \multicolumn{2}{c}{ A-SMC } & $\mathrm{L}_{1}(\mathrm{~mm})$ & $\mathrm{L}_{2}(\mathrm{~mm})$ & $\mathrm{R}(\mathrm{mm})$ & $\mathrm{L}_{3}(\mathrm{~mm})$ & $\mathrm{L}_{4}(\mathrm{~mm})$ \\
\hline & 1 & 20 & 2 & $\mathbf{5}$ & 10 & 20 \\
\hline & 2 & 22 & 2 & 6 & 10 & 20 \\
\hline
\end{tabular}

Fig. 3. Used specimen dimensions for the optimization methodology.

stress field can be considered to be homogeneous together with a constant strain rate inside the gauge length (see an example of evolution in Fig. 5). One can see that, even for the higher imposed displacement velocity; optimal conditions are applied to the specimen for tensile stress less than $5 \mathrm{MPa}$. Moreover, Fig. 4(b) show the average value of the strain rate obtained inside the gauge length for different values of radius and imposed displacement velocity. One can see that strain rate for optimized specimens can be subjected to strain rates of more than $100 \mathrm{~s}^{-1}$. The latter one can also be evaluated theoretically on the basis of the imposed velocity, such as: $\dot{\varepsilon}=\mathrm{V} / \mathrm{L}_{4}$. It should be noticed that, because of dynamic conditions, real strain rate should be $40 \%$ less than theoretical strain rate. For example, we get $60 \mathrm{~s}^{-1}$ instead of $100 \mathrm{~s}^{-1}$ for and velocity of $2 \mathrm{~m} / \mathrm{s}$ imposed on a $6 \mathrm{~mm}$ radius specimen.

iv High-speed tensile tests are achieved on the composite specimen in order to validate its optimized geometry.

Finally, the $6 \mathrm{~mm}$ radius specimen corresponds to the optimized geometry. Fig. 5 shows the spatio-temporal profiles of the longitudinal stress $\left(\sigma_{11}\right)$ calculated along the central line of the optimized A-SMC specimen. It can be observed that the shock wave
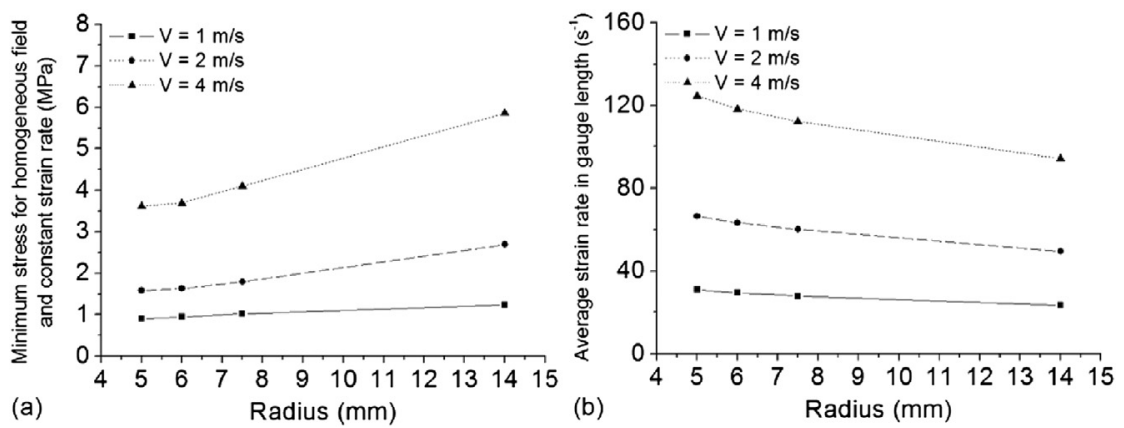

Fig. 4. Influence of the radius of the specimen; (a) Minimum stress for which homogeneous field and constant strain rate is obtained (b) Strain rate in the central zone. 

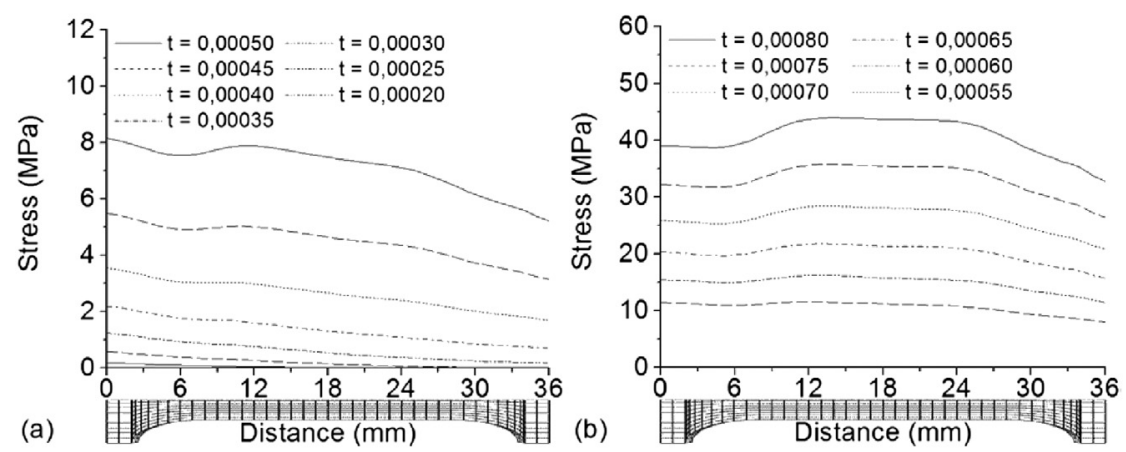

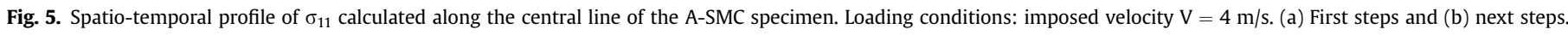

vanishes very quickly. Actually, the stress distribution becomes relatively homogeneous (see Fig 2(c)).

2.2.2.4. Strain and strain rate measurements. Local deformation is measured through a contactless technique using a high speed camera: two points were marked on the surface of the specimens defining the initial gauge length which is about $20 \mathrm{~mm}$. A high speed camera (FASTCAM-APX RS) with the capacity 250,000 frames per second was used to record pictures during high speed deformation. Image analysis is then used in order to follow the displacement of the centroid of each marked point to compute the evolution of the strain between the two points. After thresholding of the pictures, the evolution of the relative positions of the two points during deformation is computed. Then, strain measurement can be performed as shown in Fig. 6. One can note that after the damping stage characterized by a progressive increase of strain rate, the later becomes constant. Thus, strain rate can be easily determined from the slope of the linear part of the curve.

\section{Experimental results and discussion}

\subsection{Characteristics of composite}

\subsubsection{Microstructure}

Fig. 7 shows a comparison between a standard SMC microstructure and that of A-SMC. These SEM pictures obtained on polished surfaces show clearly the higher glass fibers content in A-SMC compared to standard SMC. Indeed, fibers are initially randomly oriented in the sheets plane before compression. The fibers are presented as bundles of constant length $(\mathrm{L}=25 \mathrm{~mm})$. Each bundle

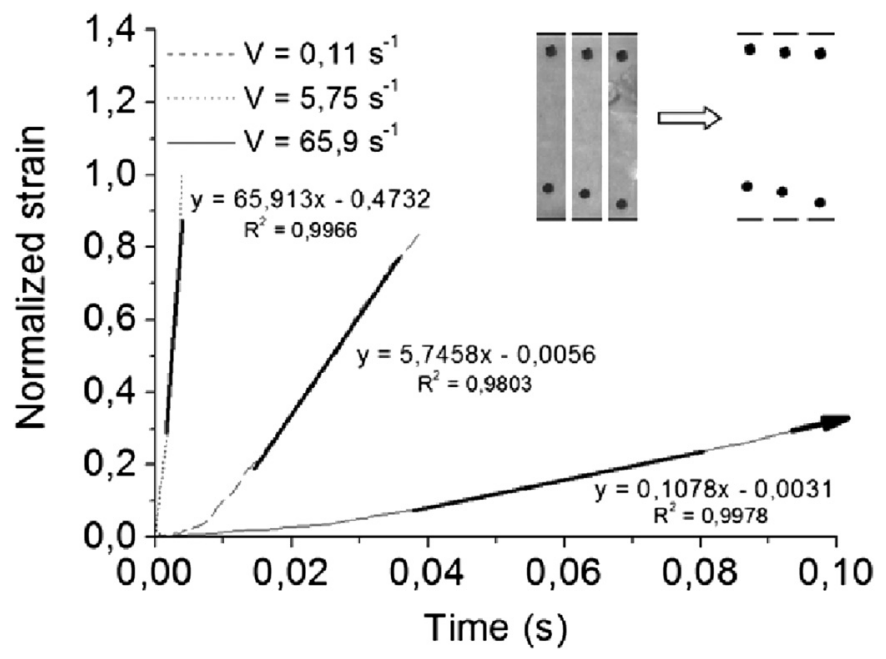

Fig. 6. Typical contactless strain measurements at various high strain rates. contains approximately 250 fibers of $15 \mu \mathrm{m}$ diameter. Glass fibers weight content is of $50 \%$.

Fig. 8 represents the distribution of the fiber content in the RO and $\mathrm{HO}$ plates as a function of the cutting orientation. It can be assumed that, due to the flowing during molding process, most of the fibers remain on the plane of the plate and tend to be oriented parallel to the Mold Flow Direction (MFD).

\subsubsection{Thermo-mechanical properties}

DMTA test is preferentially performed to study the different transitions and change of physical state of polymers. It is achieved to measure $T_{\alpha}, T_{\beta}, T_{\gamma}$ etc. In the tension (traction) configuration, DMTA tests also provide a measure of the dynamic modulus.

In this work, DMTA tests have performed according to alternating bending configuration, to study the time-temperature superposition and to plot the relaxation spectrum. It is worth mentioning that the value of modulus obtained by bending DMTA is not far from that obtained by high strain rate tensile tests.

In this study, dynamic tests are performed at room temperature. In order to measure the main transitions temperatures due to molecular mobility as a function of temperature, DMTA tests have been performed on RO samples. Fig. 9 shows the evolution of the storage modulus and the loss modulus versus temperature obtained by DMTA test. A-SMCs present a vitreous transition temperature lying between 60 and $200{ }^{\circ} \mathrm{C}$. It can be assumed that the glass transition temperature is about $130^{\circ} \mathrm{C}$. Although the storage modulus continues to slowly decrease until $50{ }^{\circ} \mathrm{C}$ due to the increase of macromolecular chain mobility, it can be assumed that at ambient temperature A-SMCs remain rigid.

\subsection{Validation of the optimization procedure}

Fig. 10 shows an example of strain evolution during a $2 \mathrm{~m} / \mathrm{s}$ imposed velocity tensile test. Strain rate is stabilized after a measured rise time of about $1.3 \times 10^{-4} \mathrm{~s}^{-1}$. Moreover, it can be shown that at this time, the material still behaves elastically. Actually, the first non linearity is four time higher than the tensile stress at equilibrium. Thus, it can be assumed that the equilibrium of the specimen is reached before the end of the yield strength. Thus, the measurement of the Young's modulus is reliable. Moreover, a comparison between experimental and numerical evolution of the strain in the central zone of the specimen (obtained for the optimized geometry) is also shown in Fig. 10. A very good correlation is observed.

One can note that after $10^{-4} \mathrm{~s}$, the strain rate is also stabilized and has a rough value of $60 \mathrm{~s}^{-1}$. However, according to the finite elements calculations, the measured strain rate value is $40 \%$ less than the theoretical one $\left(100 \mathrm{~s}^{-1}\right)$. As discussed above, this difference is due to inertial effects. On the basis of the very good agreement between the obtained experimental curves and 

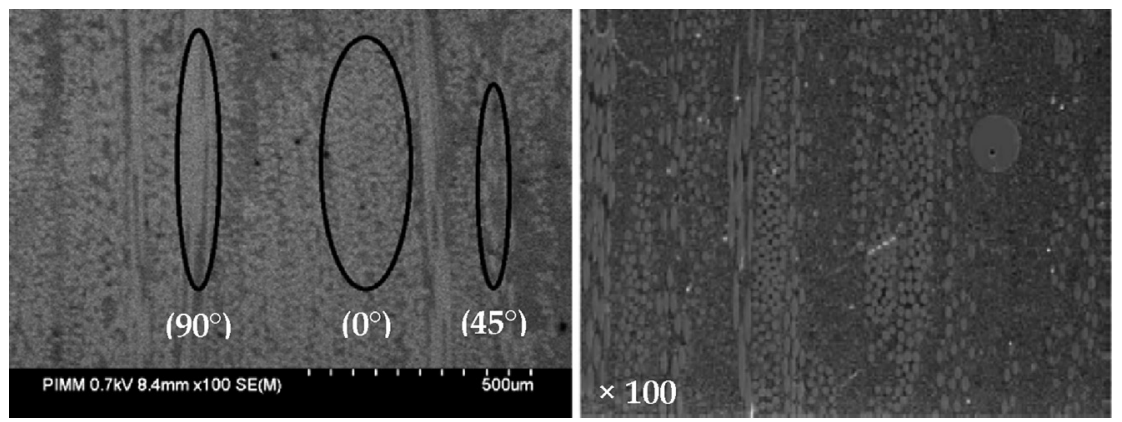

Fig. 7. Microstructure of A-SMC (left) and standard SMC (right): Randomly oriented bundle of fibers.

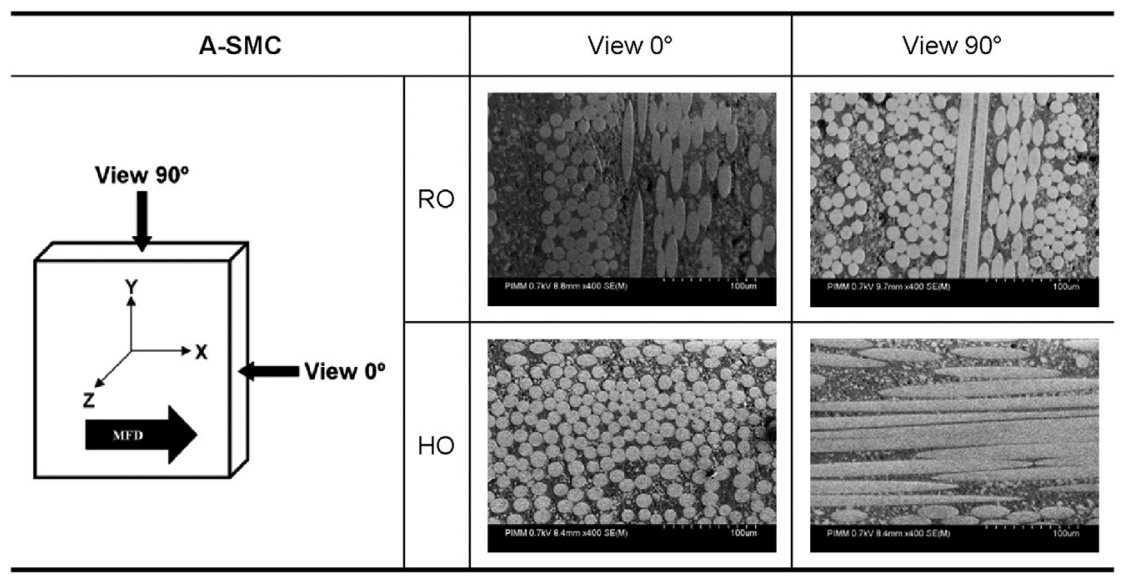

Fig. 8. Orientation of the fibers inside bundles in A-SMC.

numerical results, one can claim that our optimization procedure and the proposed geometry are validated.

\subsection{High strain rate tensile curves}

The stress-strain curves can be described by three stages:

(i) Linear elastic behavior,

(ii) Damage initiation corresponding to a knee point (apparition of a non-linear behavior),

(iii) Damage propagation corresponding to a second linear stage.

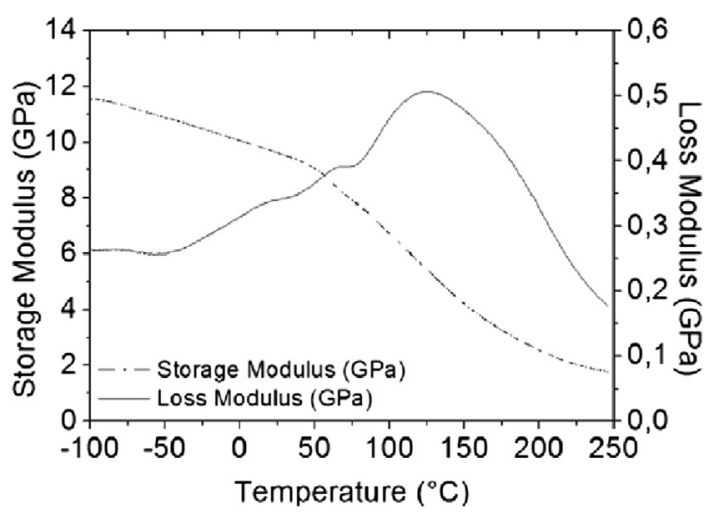

Fig. 9. DMTA test performed on RO sample.
In Fig. 11, stress-strain $(\sigma-\varepsilon)$ tensile curves are plotted for several strain rates. Tensile curves obtained for $\mathrm{RO}, \mathrm{HO}-90^{\circ}$, and $\mathrm{HO}-0^{\circ}$ show clearly that the overall behavior is highly load-rate dependent. Indeed, under rapid tensile load, A-SMC composites exhibit typically a non-linear response. It should be indicated that, in these curves, the part concerning delamination phenomena was eliminated for favorable comparison. Delamination effect will be discussed in section 3.4. Material mechanical characteristics have been estimated, as a function of strain rate. Fig. 11 show that initial slopes of the stress-strain curves are roughly identical for the range of tested strain rate values. Therefore, it means that the elastic modulus remains insensitive to strain rate. Young's moduli have a rough average value of $12,14.5$ and $18.5 \mathrm{GPa}$ for $\mathrm{HO}-90^{\circ}-$, $\mathrm{RO}$ and $\mathrm{HO}-0^{\circ}, \mathrm{A}-\mathrm{SMCs}$ respectively.

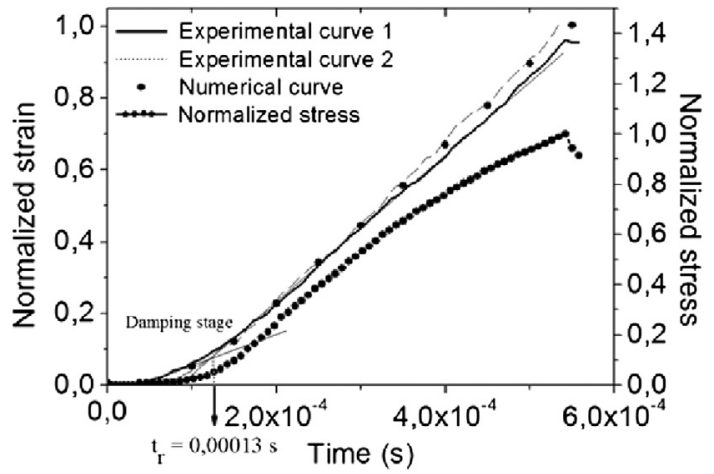

Fig. 10. Evolution of strain and stress in the central zone of the specimen. Comparison between experimental and numerical results obtained for the optimized geometry for A-SMC composites. 

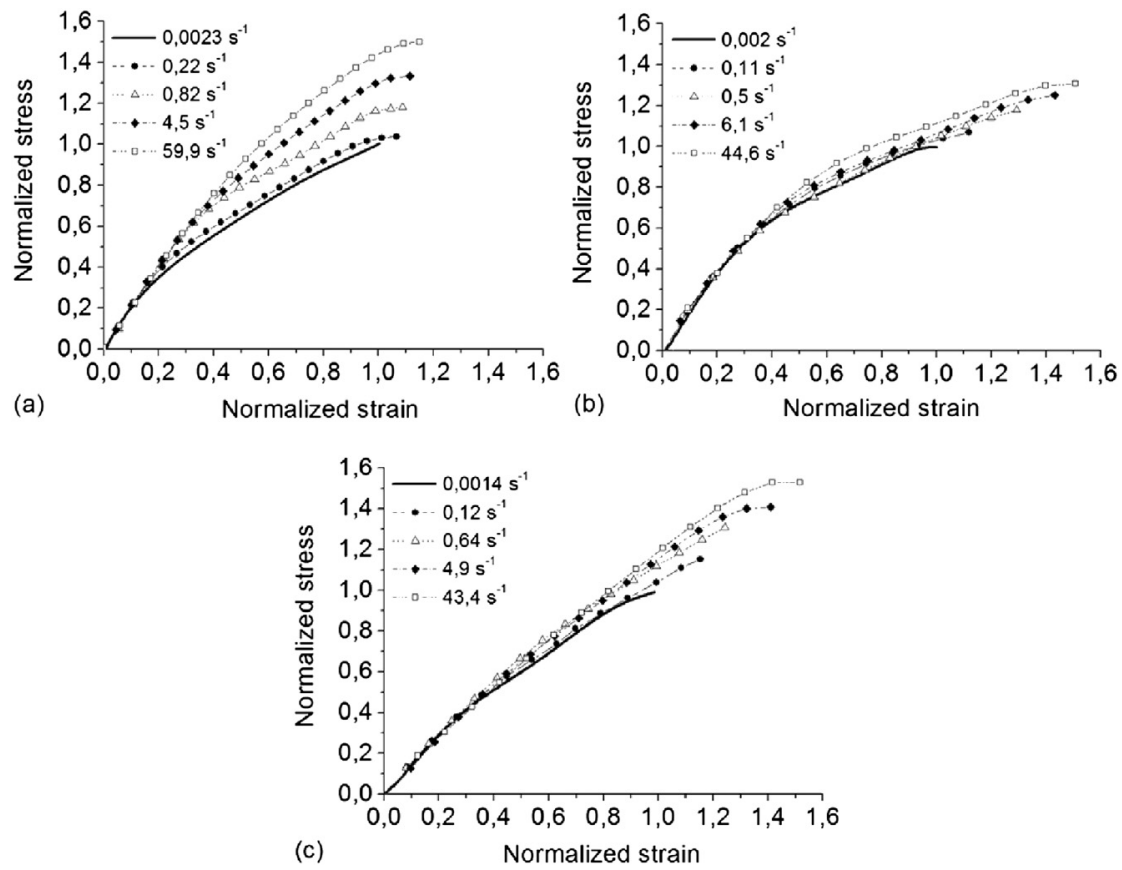

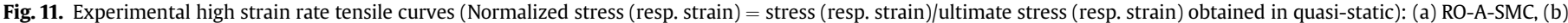
$\mathrm{HO}-90^{\circ}-\mathrm{A}-\mathrm{SMC}$ and (c) HO- $0^{\circ}-\mathrm{A}-\mathrm{SMC}$.

\subsection{Effects of strain-rate on the overall tensile response}

Material characteristics, namely Young's modulus (E); damage thresholds corresponding to the first non-linearity ( $\sigma_{\text {threshold; }}$ $\left.\varepsilon_{\text {threshold }}\right)$ and ultimate stress and strain ( $\left.\sigma_{\text {ultimate }} ; \varepsilon_{\text {ultimate }}\right)$ are shown in Figs. 12 and 13. Note that the ultimate characteristics correspond to the maximum stress level (before delamination when it occurs). Fig. 12 enables to emphasize that the material elastic modulus measured in the first stage of the stress-strain curve remain insensitive to the strain rate. However, the non-linear overall response of the A-SMC is drastically influenced by strain rate. Indeed, one can note that the damage threshold (Fig. 13), in terms of stress and strain, increases with strain rate. In fact, in the case of $\mathrm{HO}-0^{\circ}$, when varying the stain rate from the quasi-static to $100 \mathrm{~s}^{-1}$, an increase of $63 \%$ of the stress damage threshold is shown. On the other hand, the ultimate stress shows an increase of $34 \%$.

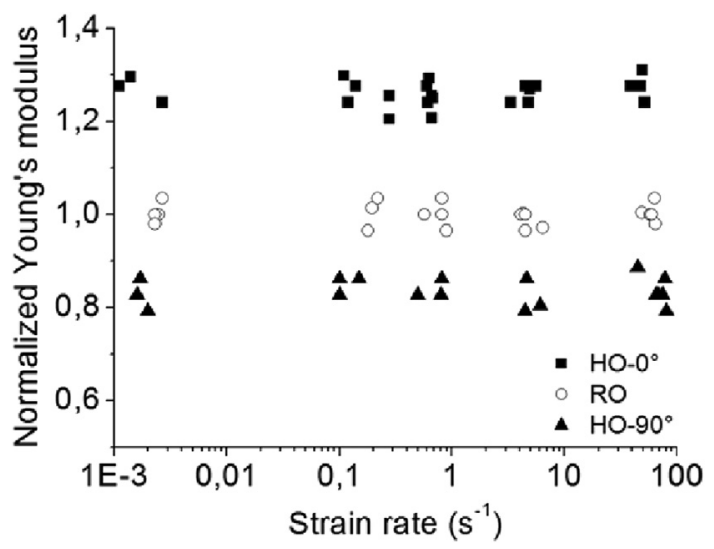

Fig. 12. Evolution of the normalized Young's modulus vs. strain rate (Normalized Young's modulus = Young's modulus/average Young's modulus obtained for quasistatic for RO-A-SMC).
In accordance to results obtained on a standard SMC [12], as the strain rate increases, noticeable effects consist of a delayed damage onset (delay of the knee-point) and ultimate stress. It can be established that the strain rate brings about a viscous nature of damage initiation and propagation. Like for standard SMC, A-SMCs also present a visco-damageable behavior. However, it must be noticed that, contrary to standard SMCs, the non-linear slope of the third stage of the A-SMCs curves (corresponding to the damage propagation stage) is also rate sensitive especially for RO A-SMC. Moreover, one can notice that for all microstructure orientation, no significant strain rate effect is noticed on the ultimate strain.

\subsection{Damage mechanisms investigation}

In order to understand the physical origin of the damage delay, it is necessary to perform experimental investigations at the microscopic scale in order to identify the corresponding damage mechanisms.

The first investigations concerns quasi-static $(0.5 \mathrm{~mm} / \mathrm{min})$ bending behavior performed on HO-A-SMC composite. In order to identify the influence of the microstructure on damage mechanisms occurring at the local scale, four points bending tests have been performed inside a SEM on $\mathrm{HO}-0^{\circ}$ and $\mathrm{HO}-90^{\circ}$ rectangular specimens. For both orientations, debonding at the fiber-matrix interface appears clearly to be the predominant damage mechanism. Interface debonding mostly appears on the fibers oriented orthogonally to the principal stress direction $\left(90^{\circ}\right.$ oriented fibers) due to high local normal stresses at the interface. Coalescence of interface failure between adjacent fibers leads to localized transverse cracks appearing on several locations in the $90^{\circ}$ oriented bundles. Propagation of these cracks into the matrix can also occur but the high content of fibers leads, in general, to the bifurcation of these cracks around surrounding more disoriented bundles of fibers. Then, pseudo-delamination between bundles is initiated. Fiber breakage can also appear at the end of the test just before failure. Interface debonding coupled to pseudo-delamination finally leads to failure by coalescence of the microcracks. 

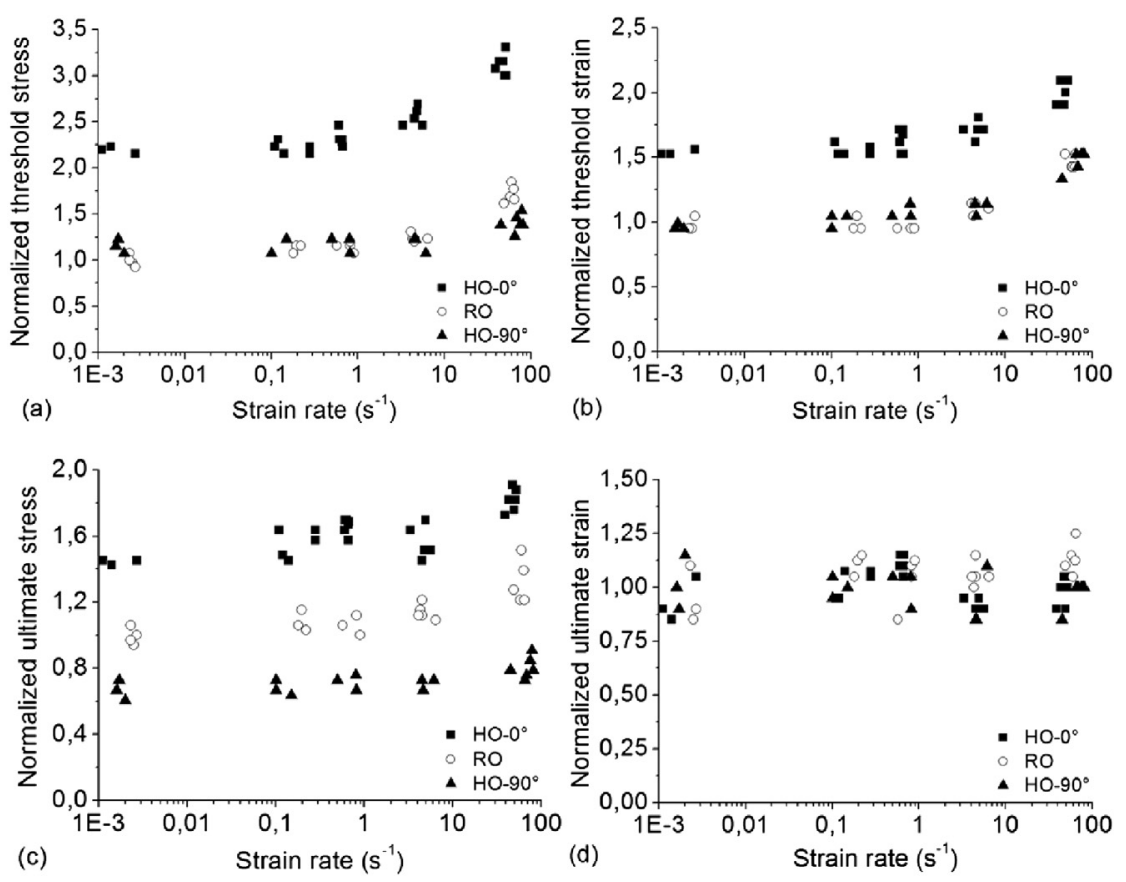

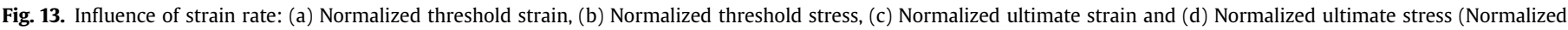
value $=$ current value/average value obtained for quasi-static tests performed on RO-A-SMC).

However, the thresholds of fiber-matrix interface damage and delamination are very dependant of the orientation of the sample. Fig. 14 shows for each orientation a first picture obtained at the initiation of the fiber-matrix interface debonding and a second one for the ultimate stress corresponding to pseudo-delamination just before failure. It has been shown that, for $\mathrm{HO}-0^{\circ}$, interface failure remains limited while pseudo-delamination is favored. On the other hand, when the fibers are oriented perpendicularly to the principal stress direction, pseudo-delamination is limited when fiber-matrix interface becomes predominant. Thus, it can be conclude that two principal mechanisms are in competition: fibermatrix interface debonding and pseudo-delamination. Moreover, the relative participation of each mechanism strongly depends on the orientation of the fibers.

On the other hand, SEM observations have been performed on the fracture surfaces for tensile specimens for quasi-static and high strain rate (around $100 \mathrm{~s}^{-1}$ ) loadings. Note that, in all micrographs shown after, the tensile direction corresponds to the horizontal direction.

SEM analysis performed on tensile specimens highlight the same damage mechanisms as shown in quasi-static bending test: fiber-matrix interface debonding and pseudo-delamination (see Fig. 15). These two mechanisms are observed for both quasi-static and dynamic tests regardless of the orientation of the bundles of fibers.

Fig. 16(a)-(c) shows fiber-matrix interface debonding for $0^{\circ}$, $45^{\circ}$, and $90^{\circ}$ oriented fibers relative to the tensile direction. One can notice that broken interfaces are always surrounded by pieces of matrix. This indicates high strength properties of the fiber-matrix interface for both quasi-static and dynamic loading.

In Fig. 17, it is noticeable to see that during pseudodelamination, bundles of fibers are pulled out from each other

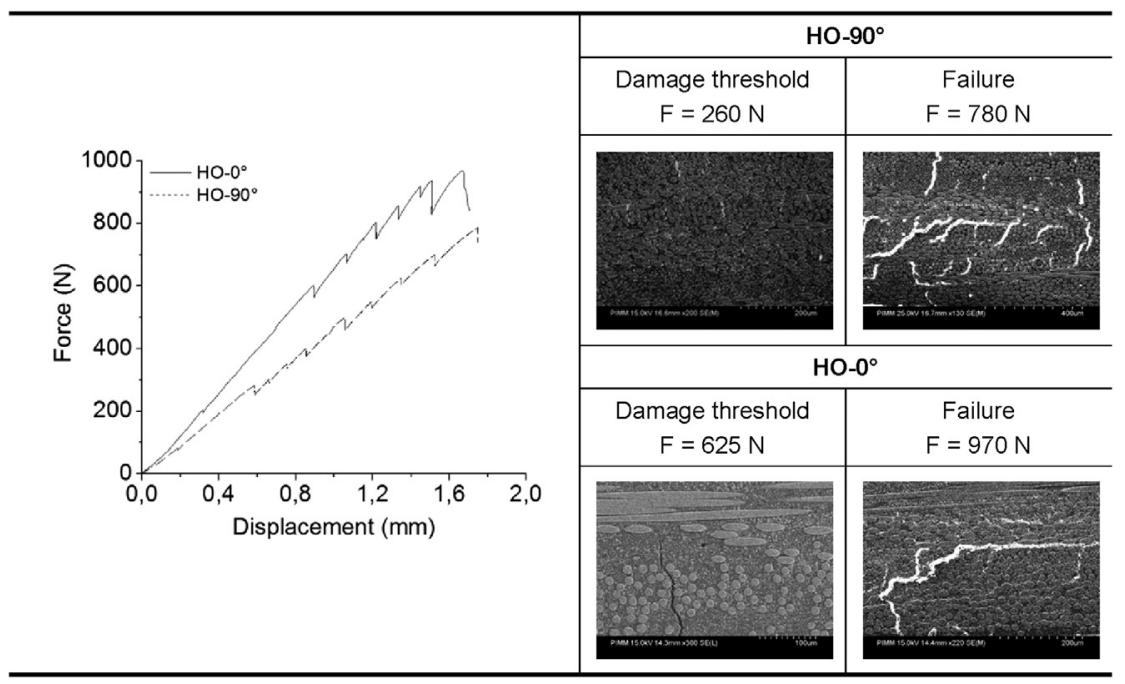

Fig. 14. Damage mechanisms under bending loading for HO-A-SMC composites. 


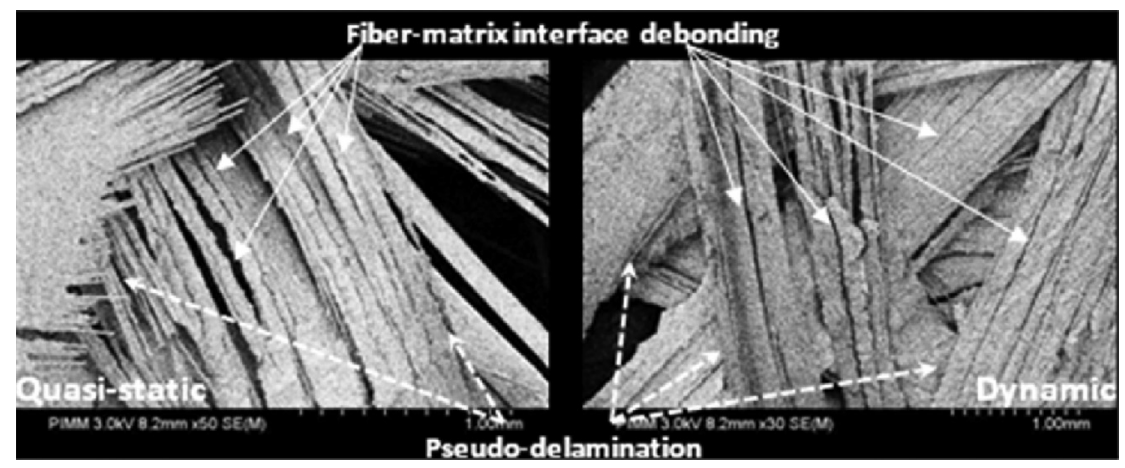

Fig. 15. Damage mechanisms for quasi-static and dynamic tensile tests.
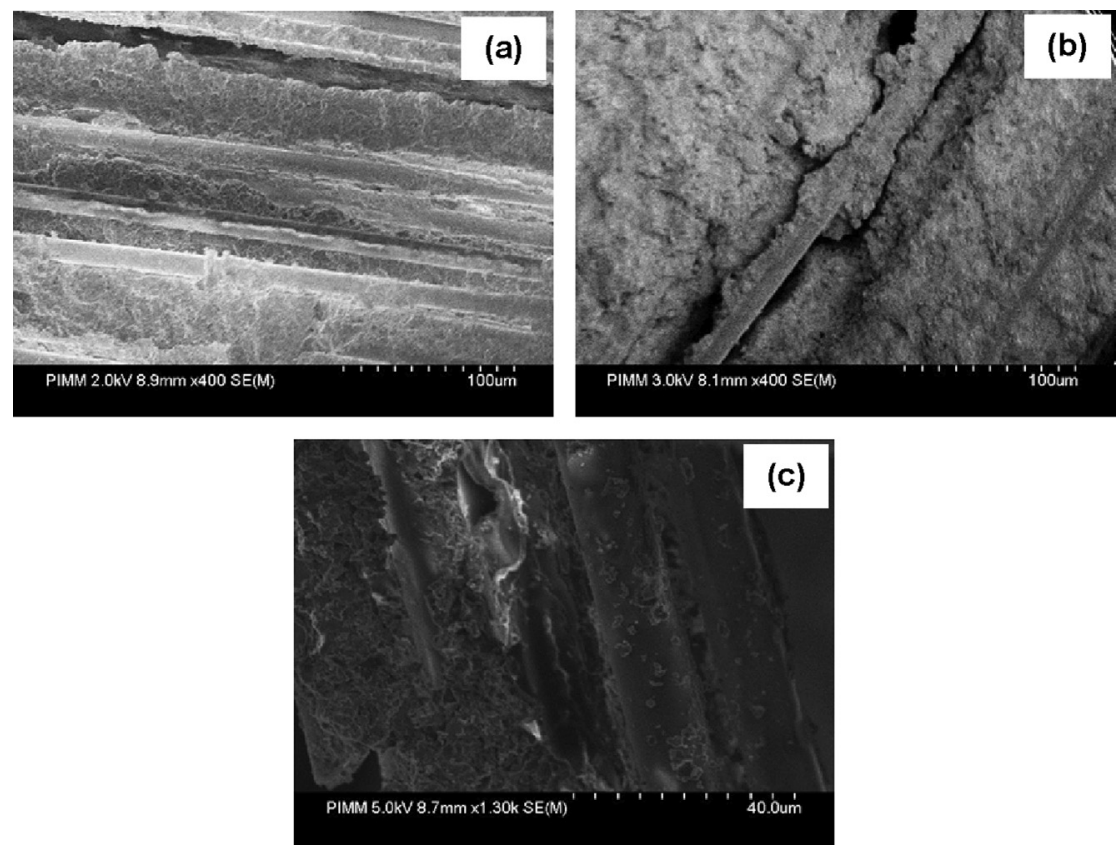

Fig. 16. Fiber-matrix interface debonding for several fiber orientation (a) $0^{\circ}$ (around $100 \mathrm{~s}^{-1}$ ), (b) $45^{\circ}$ (around $100 \mathrm{~s}^{-1}$ ), (c) around $90^{\circ}$ (quasi-static).

simultaneously with breakage of the surrounding matrix. See also Fig.16(b) for higher magnification.

In a further paper, we will show how interrupted tensile tests $[12,19]$ enable to quantify the strain rate effect at the local scale through the analysis of the evolution of the fiber-matrix interface failure density.

\subsection{Pseudo-delamination mechanism}

In this section, the influence of the loading rate and orientation of fibers on pseudo-delamination is investigated. Tensile tests have been performed until specimen total failure under variable strain rates from quasi-static $\left(0.001 \mathrm{~s}^{-1}\right)$ to $100 \mathrm{~s}^{-1}$. All the results shown above have been analyzed only until the ultimate stress. However, because of the pseudo-stratificated microstructure, local delamination between the bundles of fibers can occur before the total separation into two parts. This phenomenon can greatly participate to energy absorption during crash. In this section, we focus on the influence of the microstructure and imposed velocity on the magnitude of the pseudo-delamination.

Fig.18(a) shows a typical evolution of the tensile strain until total separation into two parts including the deformation provided by

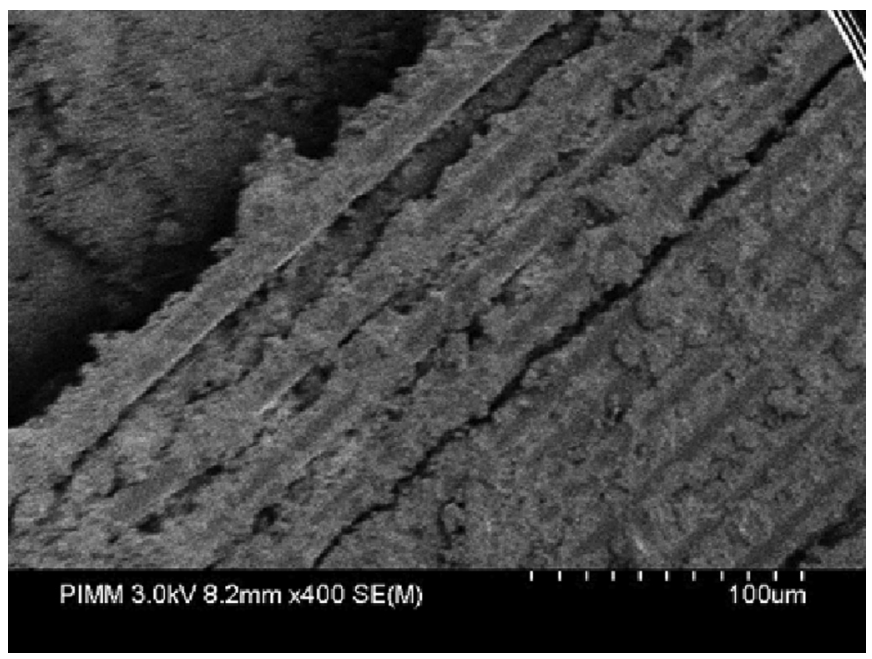

Fig. 17. Pseudo-delamination through surrounding matrix breakage. 

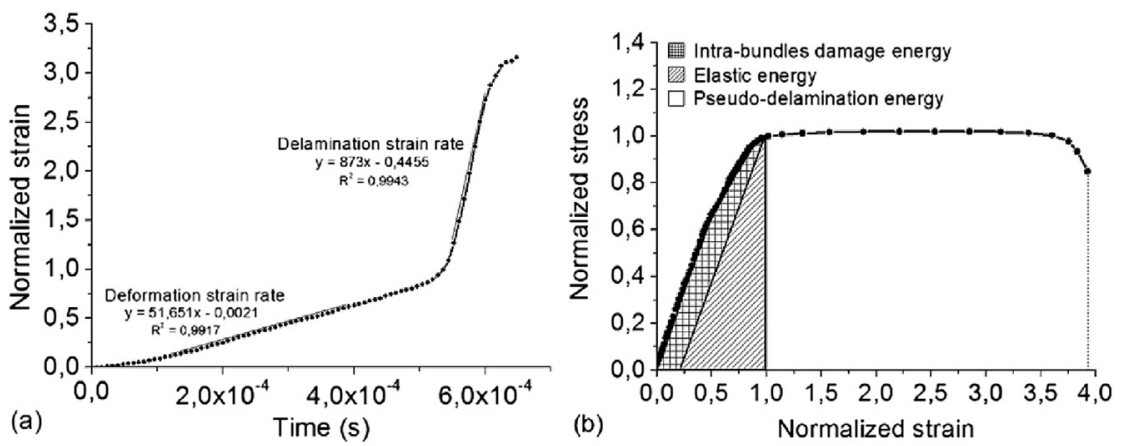

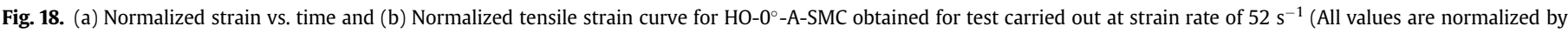
dividing to the value corresponding to the ultimate stress and before delamination).

local delaminations between bundles of fibers. For high speed tensile tests, pseudo-delamination stage duration appears to be very short (about $10^{-4} \mathrm{~s}$ ) compared to that of the elastic and damage stages (about $5.5 \times 10^{-4} \mathrm{~s}$ ). Tensile strain rate during delamination is more than 15 time higher. Stress-strain curves in tension can also be plotted as shown in Fig. 18(b). The area under the stress-strain curve corresponds to the total strain energy per unit volume absorbed by the composite until complete separation into two parts: $\mathrm{E}^{\mathrm{T}}$. The area under the curve until the ultimate stress corresponds to the elastic and damage energy: $E^{\mathrm{e}}$ and $\mathrm{E}^{\mathrm{d}}$ respectively. As discussed before, damage energy is mostly due to the debonding at the fiber-matrix interface inside the bundles (intrabundles damage). Then, from the ultimate stress until the total separation into two parts, the area under the curve corresponds to absorbed energy by delamination between the bundles: $E^{D}$. It is very obvious that the pseudo-delamination can highly participate to energy dissipation during a crash test. In fact, in the case of HO$0^{\circ}$ tensile tests performed under high strain rates, absorbed energy by pseudo-delamination can be 6 time higher than the absorbed energy during elastic and damage stages.

Fig. 19 presents typical whole curves for different microstructure and different imposed velocity together with macroscopic failure photography. Qualitatively, one can see that increasing loading speed leads to more intensive pseudo-delamination regardless of orientation of fibers. Relative elastic, damage and pseudo-delamination energy values; $\mathrm{E}^{\mathrm{e}} / \mathrm{E}^{\mathrm{T}}, \mathrm{E}^{\mathrm{d}} / \mathrm{E}^{\mathrm{T}}, \mathrm{E}^{\mathrm{D}} / \mathrm{E}^{\mathrm{T}}$ respectively have been measured (area under the curves (see Fig. 18(b)). Relative damage and pseudo-delamination evolution are plotted in Fig. 20

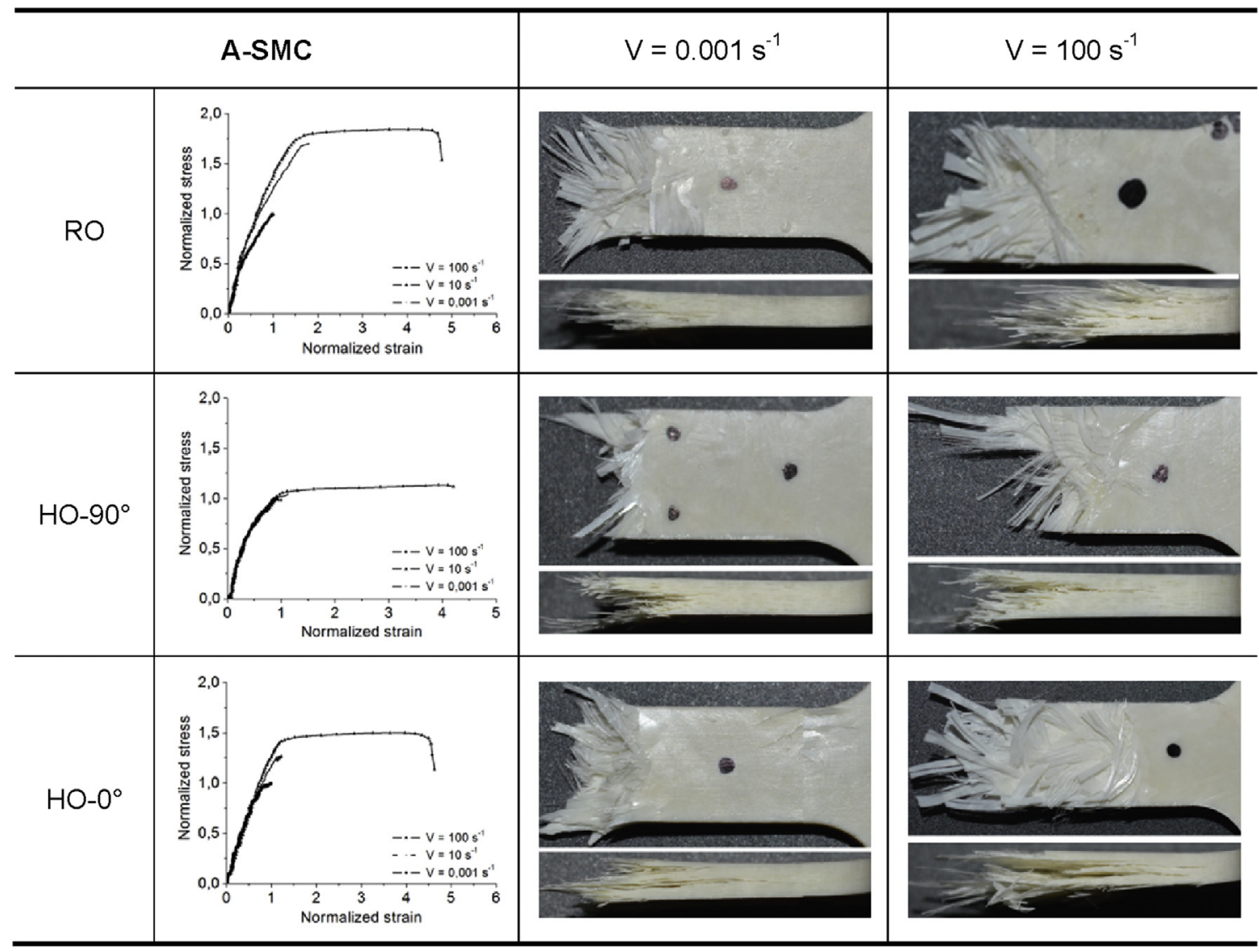

Fig. 19. Typical whole curves for different microstructure and different imposed velocity together with macroscopic failure appearance. 


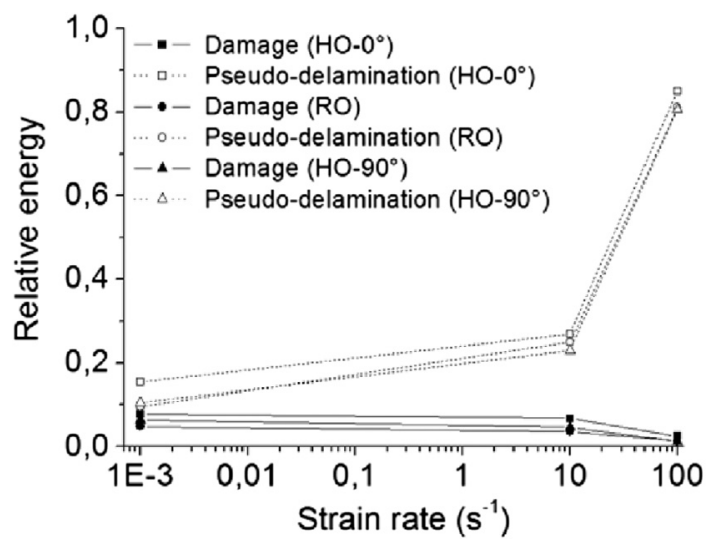

Fig. 20. Evolution of the relative damage and pseudo-delamination energy versus strain rate.

as a function of strain rate. One can clearly conclude that high loading speed favor the increase of the pseudo-delamination intensity. Moreover, Fig. 21 shows the evolution of the ratio $\mathrm{E}^{\mathrm{D}} / \mathrm{E}^{\mathrm{D}} \mathrm{RO}$ where $\mathrm{E}^{\mathrm{D}}{ }_{\mathrm{RO}}$ is the pseudo-delamination energy measured for RO-ASMC for a $10 \mathrm{~s}^{-1}$ applied strain rate. It is obvious to note that oriented fibers in the tensile direction also favor delamination.

It is important to notice that the end of experimental curves (Fig. 19) represents the last stage of the damage mechanisms propagation and accumulation prior to the macroscopic failure of the specimen. Two kinds of failure mechanisms have been observed.

- The first one appears for the lower strain rate values independently of the microstructure: it corresponds to the coalescence and the accumulation of the fiber-matrix interface cracks through the matrix between bundles of fibers [12].

- The second one appears for higher strain rate values independently of the microstructure: in this case, the pseudodelamination becomes the predominant failure mechanism. Fiber-matrix interface cracks coalescence in the matrix is limited by the pseudo-delamination which becomes the predominant failure mechanism at high strain rate. A plateau is observed before the failure corresponding to the propagation of the cracks around the bundles of fiber prior to the coalescence leading to the final failure (Fig. 19). This mechanism is more intense for oriented microstructure (Fig. 21).

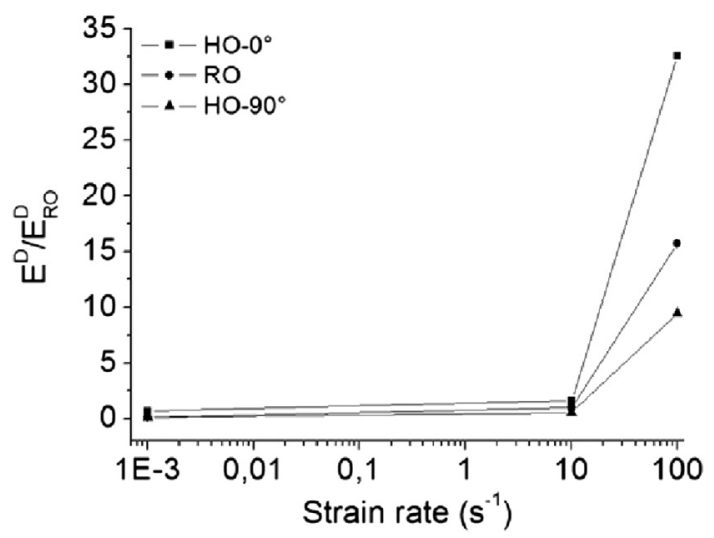

Fig. 21. Evolution of the pseudo-delamination energy for various fiber orientations and strain rates.
In conclusion, pseudo-delamination strongly participates to energy dissipation. Thus, this mechanism can't be neglected for crash simulations.

\section{Conclusion}

A-SMC is a high mechanical performance SMC based on vinylester resin and reinforced with high content of glass fibers ( $>50 \%$ weight content) compare to standard SMC (30\% weight content). An original method for high strain rate testing optimization has been validated for moderate rates up to $100 \mathrm{~s}^{-1}$. A damping joint have been optimized in terms of thickness and material properties. Then, the resulting experimental conditions (rise time and imposed velocity) were input into a numerical computations using ABAQUS FE explicit code. Iterative calculations led to determine the optimal specimen geometry through the analysis of the stress wave propagation occurring during a high-speed tensile test. It has been demonstrated that the resulting specimen design generates uniform strain and stress fields and constant strain-rate into the tested specimen.

The developed experimental methodology based on dynamic tensile tests has contributed to emphasize the strain rate effects on the overall behavior of A-SMC composites. The use of a servohydraulic testing machine has been suitable to examine strainrate effects on overall A-SMC (RO and $\mathrm{HO}$ ) behavior for moderate rates up to $100 \mathrm{~s}^{-1}$. The strain rate is measured through a contactless technique using a high speed camera. Moreover, SEM micrographs show that most of the fibers are more or less oriented according to the disposition of the A-SMC prepreg and process parameters. In order to represent as well the structural response during an automotive crash, the strain rate effects on the mechanical behavior of two type of microstructure have been studied: Randomly Oriented fibers (RO) and Highly Oriented fibers (HO). Experimental results of high strain rate tensile tests show that the composite behavior is strongly strain-rate dependent although the Young's modulus remains constant for RO and HO samples when strain rate increases. On the contrary, as the strain rate increased, noticeable effects consist of a delayed damage onset: for example, the stress damage threshold of $\mathrm{HO}-0^{\circ}$-A-SMC showed an increase of $63 \%$ when increasing the strain rate from quasi-static $\left(0.001 \mathrm{~s}^{-1}\right)$ to $100 \mathrm{~s}^{-1}$. In the same time, a $40 \%$ increase of the ultimate stress can be observed when the ultimate strain does not seem to be significantly affected.

Moreover, SEM analysis performed on broken tensile specimens highlight the same damage mechanisms as shown in quasi-static bending tests: fiber-matrix interface debonding and pseudodelamination between bundles of fibers. Until the ultimate stress, damage energy is mostly due to the debonding at the fiber-matrix interface inside the bundles (intra-bundles damage). However, it has been shown that the pseudo-delamination also greatly participates to the energy absorption. Then, the second part of the curve appearing as a plateau from the ultimate stress until the total separation into two parts cannot be neglected. Indeed, the area under the curve corresponding to the absorbed energy by pseudodelamination between bundles can be ten times higher than the energy absorbed through fiber-matrix interface debonding (intrabundles damage). It is important to note that increasing loading speed and oriented fibers in the tensile direction favor a more intensive pseudo-delamination. These two effects have been also quantified. This study clearly establishes that the strain rate effect is related to a certain viscous nature of both intra-bundles and pseudo-delamination damage evolution. One can speak about a time dependent visco-damage behavior leading to the increase of the fiber-matrix and inter-bundles interfaces strengths. 
Consequently, it is very obvious that intra-bundle damage and pseudo-delamination highly participate to energy dissipation during a crash test and that stain rate effect on these two damage mechanisms cannot be neglected for automotive structural crashworthiness simulations. The optimized experimental methodology will provide the experimental framework to develop, identify and validate a multi-scale model integrating the material microstructure influence. This model will be used as a simulation tool for the optimization of A-SMC composite structure crashworthiness in accordance with design requirements and material microstructure distribution.

\section{References}

[1] Le TH, Dumont PJJ, Orgéas L, Favier D, Salvo L, Boller E. X-ray phase contrast microtomography for the analysis of the fibrous microstructure of SMC composites. Compos Part A Appl Sci Manuf 2008;39(1):91-103.

[2] Palmer J, Savage L, Ghita OR, Evans KE. Sheet moulding compound (SMC) from carbon fibre recyclate. Compos Part A Appl Sci Manuf 2010;41(9):1232-7.

[3] Fitoussi J, Guo G, Baptiste D. A statistical micromechanical model of anisotropic damage for S.M.C. composites. Compos Sci Technol 1998:58(5):759-63.

[4] Wulfsberg J, Herrmann A, Ziegmann G, Lonsdorfer G, Stö $\beta$ N, Fette M. Combination of carbon fiber sheet moulding compound and prepreg compression moulding in aerospace industry. Procedia Eng 2014;81:1601-7.

[5] Feuillade V, Bergeret A, Quantin J, Crespy A. Characterisation of glass fibres used in automotive industry for SMC body panels. Compos Part A Appl Sci Manuf 2006;37(10):1536-44.

[6] Lu J, Khot S, Wool RP. New sheet molding compound resins from soybean oil. I. Synthesis and characterization. Polymer 2005;46(1):71-80.

[7] Guiraud O, Dumont PJJ, Orgéas L, Favier D. Rheometry of compression moulded fibre-reinforced polymer composites: rheology, compressibility, and friction forces with mould surfaces. Compos Part A Appl Sci Manuf 2012;43(11):2107-19.

[8] Jendli Z, Meraghni F, Fitoussi J, Baptiste D. Multi-scales modeling of dynamic behaviour for discontinuous fibre SMC composites. Compos Sci Technol 2009;69(1):97-103.

[9] Dear JP, Brown SA. Impact damage processes in reinforced polymeric materials. Compos Part A Appl Sci Manuf 2003;34(5):411-20.

[10] Jendli Z, Meraghni F, Fitoussi J, Baptiste D. Micromechanical analysis of strain rate effect on damage evolution in sheet molding compound composites. Compos Part A Appl Sci Manuf 2004;35(7-8):779-85.

[11] Jendli Z, Fitoussi J, Meraghni F, Baptiste D. Anisotropic strain rate effects on the fibre-matrix interface decohesion in sheet moulding compound composites. Compos Sci Technol 2005;65(3-4):387-93.

[12] Fitoussi J, Meraghni F, Jendli Z, Hug G, Baptiste D. Experimental methodology for high strain-rates tensile behaviour analysis of polymer matrix composites. Compos Sci Technol 2005;65(14):2174-88.

[13] Le Corre S, Orgéas L, Favier D, Tourabi A, Maazouz A, Venet CC. Shear and compression behaviour of sheet moulding compounds. Compos Sci Technol 2002;62(4):571-7.

[14] Naik NK, Yernamma P, Thoram NM, Gadipatri R, Kavala VR. High strain rate tensile behavior of woven fabric E-glass/epoxy composite. Polym Test 2009;29(1):14-22.

[15] Brown KA, Brooks R, Warrior NA. The static and high strain rate behaviour of a commingled E-glass/polypropylene woven fabric composite. Compos Sci Technol 2009;70(2):272-83.

[16] Jacob GC, Starbuck JM, Fellers JF, Simunovic S, Boeman RG. Strain rate effects on the mechanical properties of polymer composite materials. J Appl Polym Sci 2004;94(1):296-301.

[17] Hsiao HM, Daniel IM. Strain rate behavior of composite materials. Compos Part B Eng 1998;29(5):521-33.

[18] Meraghni F, Desrumaux F, Benzeggagh ML. Implementation of a constitutive micromechanical model for damage analysis in glass mat reinforced composite structures. Compos Sci Technol 2002;62(16):2087-97.

[19] Fitoussi J, Bocquet M, Meraghni F. Effect of the matrix behavior on the damage of ethylene-propylene glass fiber reinforced composite subjected to high strain rate tension. Compos Part B Eng 2013;45(1):1181-91. 